\title{
The skeleton: a multi-functional complex organ. New insights into osteoblasts and their role in bone formation: the central role of PI3Kinase
}

\author{
Anyonya R Guntur and Clifford J Rosen \\ The Musculoskeletal Laboratory, Maine Medical Center Research Institute, Center for Clinical and Translational Research, 81 Research Drive, Scarborough, \\ Maine 04074, USA \\ (Correspondence should be addressed to C J Rosen; Email: crofen@gmail.com)
}

\begin{abstract}
Studies on bone development, formation and turnover have grown exponentially over the last decade in part because of the utility of genetic models. One area that has received considerable attention has been the phosphatidylinositol 3-kinase (PI3K) signaling pathway, which has emerged as a major survival network for osteoblasts. Genetic engineering has enabled investigators to study downstream effectors of PI3K by directly overexpressing activated forms of AKT in
\end{abstract}

cells of the skeletal lineage or deleting Pten that leads to a constitutively active AKT. The results from these studies have provided novel insights into bone development and remodeling, critical processes in the lifelong maintenance of skeletal health. This paper reviews those data in relation to recent advances in osteoblast biology and their potential relevance to chronic disorders of the skeleton and their treatment.

Journal of Endocrinology (2011) 211, 123-130

\section{Introduction}

Skeletal tissue in vertebrates develops in two ways, through either intramembranous or endochondral ossification. The former is required for cranial development, while the latter is the mechanism for bone formation in the limb and axial skeleton. Osteoblasts, the bone forming cells of the skeleton, are essential in both these pathways (Kronenberg 2003). Osteoblasts originate from mesenchymal stem cells (MSC) that are multipotent and can differentiate into a number of lineages including bone, fat, muscle, and cartilage. This allocation is dependent on extracellular signaling and the activation or repression of transcription factors that affect common intracellular signaling networks. The Wnt/ $\beta$-catenin and the insulin/growth factor/phosphatidylinositol 3-kinase (PI3K) pathways, have been the focus of recent work and both have emerged as critical for bone development, skeletal remodeling and energy metabolism.

The Wnt/ $\beta$-catenin pathway has been the subject of several very recent reviews (Baron \& Rawadi 2007, Secreto et al. 2009, Williams \& Insogna 2009) whereas the latter (i.e. insulin/growth factor/PI3K pathway) is often considered

This paper is one of three papers that form part of a thematic review section on the skeleton: a multi-functional complex organ. The Guest Editor for this section was Colin Farquharson, Roslin Institute, University of Edinburgh, UK. solely within the framework of ligand activation rather than as a final common pathway that targets critical transcription factors to promote MSC growth and differentiation. This review outlines some of the recent advances in our understanding of the PI3K signaling system and its role in bone formation. We will first discuss the osteoblast transcriptional factors that control osteogenesis and then delineate how these are related to PI3K signaling and its downstream targets. Finally, we will discuss potential therapeutic applications of these studies.

\section{PI3K and transcriptional control of osteoblastogenesis}

PI3K is an important lipid kinase that controls a number of cellular functions including proliferation, survival, and motility in response to ligand activation. On the contrary, constitutively active PI3K signaling can lead to neoplastic proliferation because of unrestricted cell growth (Cantley, 2002). Therefore, cells have developed a mechanism to regulate this process utilizing phosphatase and tensin homolog deleted on chromosome ten (PTEN; Franke et al. 1997, Manning \& Cantley 2007). Pten was first identified as a tumor suppressor gene and later on was characterized as a lipid phosphatase (Li et al. 1997, Maehama \& Dixon 1998). PTEN works mainly by acting as a direct antagonist to the actions of 
PI3K, where it can dephosphorylate phosphatidylinositol 3,4,5-trisphosphate $\left(\mathrm{PIP}_{3}\right)$ to phosphatidylinositol 4,5bisphosphate $\left(\mathrm{PIP}_{2}\right)$ thereby negatively regulating $\mathrm{PI} 3 \mathrm{~K}$ signaling as shown in Fig. 1 (Myers et al. 1998). In the absence of Pten there is accumulation of $\mathrm{PIP}_{3}$ at the membrane to recruit PDK1 that can phosphorylate AKT at its threonine 308 residue (Alessi et al. 1997). This, in turn, leads to mechanistic target of rapamycin complex 2 (MTORC2) phosphorylating AKT at serine 473 (Sarbassov et al. 2005), resulting in a completely active AKT pathway.

Recent genetic studies of PI3K signaling reveal that AKT and its downstream targets are critical regulators of endochondral ossification. For example, double Akt1/Akt2 knockout mice have delayed bone ossification (Peng et al. 2003), whereas Akt1 knockout mice have shorter bones and delayed formation of secondary ossification centers (Ulici et al. 2009). AKT has also been shown to affect bone formation and osteoblast survival by regulating Forkhead group of transcriptional factor 3 (FOXO3; Kawamura et al.
2007). In addition, AKT in concert with bone morphogenetic protein 2 (BMP2) mediates osteoblast differentiation from mesenchymal stromal cells (Ghosh-Choudhury et al. 2002, Mukherjee et al. 2010).

\section{FOXOs}

In addition to its relatively direct role in bone formation, AKT, an AGC family kinase, can also phosphorylate other families of substrates that are critical for bone formation. Among those is the FOXOs. These transcriptional factors are not osteoblast specific as opposed to other nuclear factors such as Runx2, Osterix, and ATF4. The Forkhead group of transcriptional family members FOXO1, FOXO3, and FOXO4 are highly expressed in chondrocytes and osteoblasts (Ambrogini et al. 2010). Activated AKT can phosphorylate FOXOs and control their transcriptional activity by maintaining their retention in the cytoplasm rather than promoting their nuclear transport (Brunet et al. 1999).

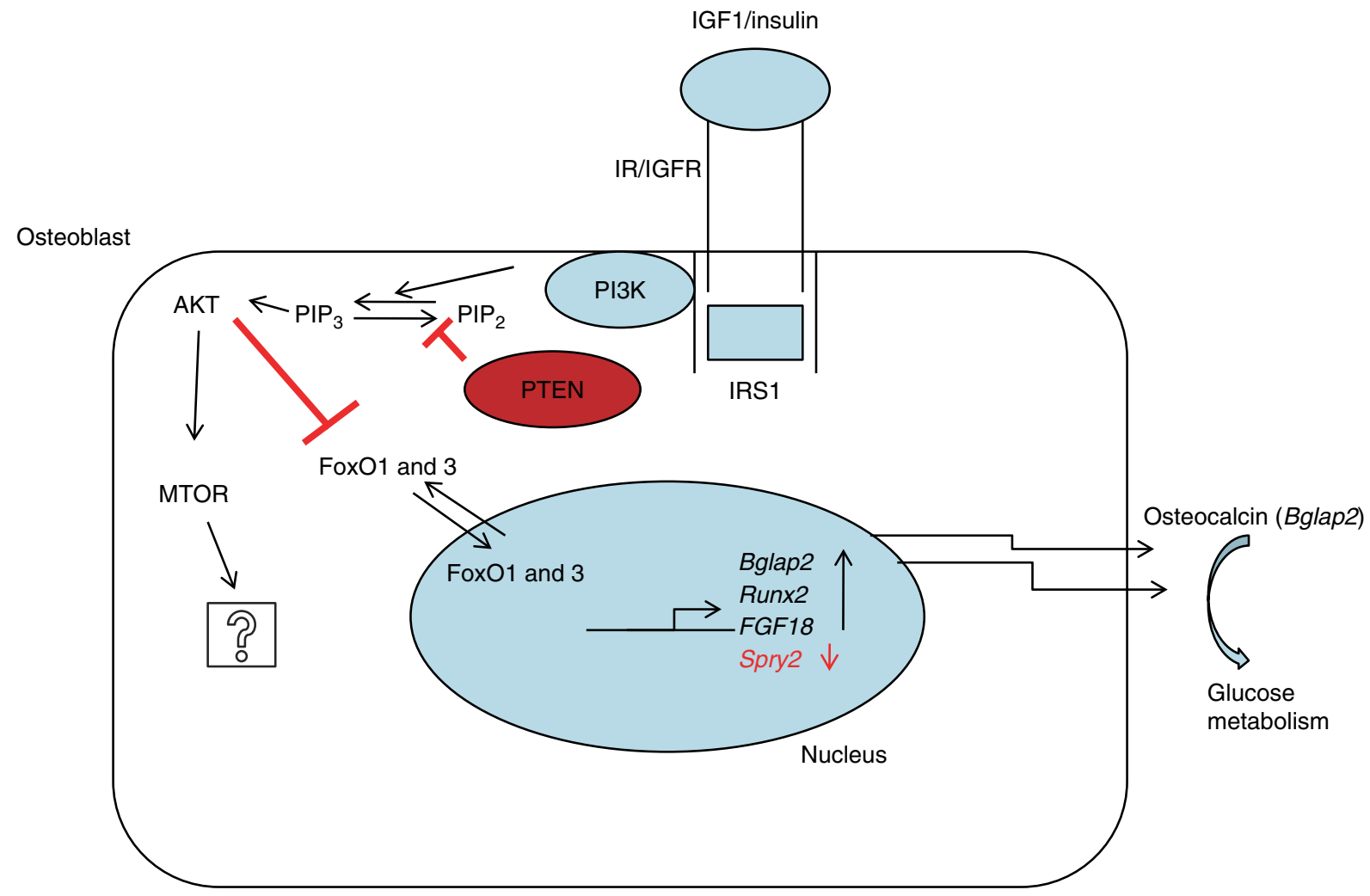

Figure 1 The model depicted above shows an osteoblast cell where phosphatidylinositol 3-kinase (PI3K) signaling is activated by a growth factor in this case insulin or insulin-like growth factor 1 (IGF1) by binding to their respective tyrosine kinase receptors which leads to binding of substrate proteins like insulin receptor substrate 1 (IRS1) that can bind to PI3K and activate it. PI3K can phosphorylate and convert phosphatidylinositol 4,5-bisphosphate $\left(\mathrm{PIP}_{2}\right)$ to phosphatidylinositol 3,4,5-trisphosphate $\left(\mathrm{PIP}_{3}\right)$ that leads to activation of AKT. AKT can phosphorylate and activate MTOR, the downstream effects of this action have not been elucidated in detail during osteogenesis. AKT can also phosphorylate and inactivate Forkhead group of transcriptional factors 1 and 3 (FOXO1 and 3 ) that leads to regulation of a number of genes that are important during osteoblastogenesis, the figure shows fibroblast growth factor 18 (FGF18) and Runx2 and Sprouty2 (Spry2). Osteocalcin (Bglap2) that is also among the genes regulated then acts in an endocrine fashion and affects glucose homeostasis. 
FOXO1 and FOXO3 have a major role in bone development by negatively regulating the transcriptional expression of key osteoblastic genes such as osteocalcin (Bglap2) and ATF4 (Rached et al. 2010a,b). FOXO1, by modulating the expression of osteocalcin and upregulating Esp (protein tyrosine phosphatase), also plays a role in glucose homeostasis (Kousteni 2010, Rached et al. 2010a,b) and both these studies showed that deletion of FOXO's strongly affects osteoblast function (Table 1). Furthermore, a study when all three FOXO factors were deleted showed an increase in osteoblast and osteocyte apoptosis due to enhanced oxidative stress resulting in loss of bone mass (Ambrogini et al. 2010). Most importantly, Ambrogini et al. (2010) demonstrated that FOXO3 was the major factor expressed in bone and overexpression in bone led to an increase in bone mass. The role of FOXO4 is not clear in osteoblasts and chondrocytes even though its expression has been shown in these cells.

\section{Runx2}

MSCs that enter the osteogenic lineage can be identified by expression of an important transcriptional factor called Runx2. Runx 2 is a member of the broader RUNX family of transcriptional factors. In humans, haploinsufficiency of Runx2 causes cleidocranial dysplasia that leads to delays in ossification of the skull and bone formation. Mouse studies of Runx2 deletion reveal embryonic lethality due to the absence of bone formation. Runx 2 controls osteoblast differentiation by upregulating the expression of several critical osteoblastic genes including osteopontin ( $S p p 1)$, bone sialoprotein $(B s p)$, and osteocalcin (Bglap2) (Ducy et al. 1997, Mundlos et al.
1997, Otto et al. 1997). Runx2 also interacts with PI3K signaling networks at various levels to control expression of p85 and p110 $\beta$ subunits of the PI3K complex (Fujita et al. 2004). Runx 2 binds to the promoter regions of these genes and interacts with coactivators thereby inducing gene expression. Recent studies have shown that FOXO1, that can be negatively regulated by active AKT signaling, can bind to RUNX2 and negatively regulate its transcriptional activity specifically relative to osteocalcin gene expression (Yang et al. 2011).

\section{Osterix}

Another important osteoblastic gene that is a target of Runx2 during osteoblast differentiation is Osterix $(S p 7)$. It is a zinc finger-containing protein homologous to the Sp group of transcriptional factors. Gene deletion studies have shown that in the absence of Osterix there is no bone formation even though there is expression of Runx2 suggesting that Osterix is downstream of Runx2 (Nakashima et al. 2002). There is also some evidence suggesting that Osterix can be transcriptionally upregulated by Runx2 (Nishio et al. 2006). The expression of this transcriptional factor starts around $12 \cdot 5 \mathrm{dpc}$ and has a major role during embryonic bone development. But deleting Osterix at different time points postnatally showed that it is also necessary for adult bone growth and resorption, by affecting osteoblast and osteocyte development and function (Zhou et al. 2010). Osterix has been shown to transcriptionally upregulate Col1a1 expression through its interaction with NFATc1 (Koga et al. 2005). However, there is no direct evidence showing that Osterix gene expression can be regulated through PI3K signaling

Table 1 Summarizes all the different knockouts and promoter Cre lines utilized to delete Pten and its downstream targets in different skeletal lineages along with some of the key observations

\author{
Conditional knockouts of Pten generated \\ by using the following mice \\ 1) a) Col2a1cre/Pten flox/flox \\ (exons 4 and 5) \\ b) Col2a1cre/Pten flox/flox \\ (exons 4 and 5) \\ c) Col2a1cre/Pten flox/flox (exon 5) \\ 2) Osteocalcin cre/Pten flox/flox \\ (exons 4 and 5) \\ 3) Dermo1cre/Pten flox/flox \\ (exons 4 and 5) \\ 4) Akt1/Akt2 knockouts \\ 5) $A k t 1$ \\ 6) myrAKT (under the control of \\ Col2a1 promoter) \\ 7) Colla1cre/FOXO1 \\ 8) a) FOXO1,3,4 and b) FOXO3 \\ overexpression
}

\section{References}

Ford-Hutchinson et al. (2007)

Yang et al. (2008)

Hsieh et al. (2009)

Liu et al. (2007)

Guntur et al. (2011)

Peng et al. (2003)

Kawamura et al. (2007)

Rokutanda et al. (2009)

Rached et al. $(2010 a, b)$

Ambrogini et al. (2010)

\section{Skeletal phenotypes observed}

Disrupted normal growth plate organization, increased skeletal formation with increased AKT and MTOR activity

Caused dyschondroplasia, decreased chondrocyte proliferation and differentiation with increased endoplasmic stress

Kyphosis, larger disorganized growth plates and vertebrae, increased marrow adipocytes

Decreased apoptosis of osteoblasts leading to increased bone formation through the animals life span

Deletion in osteoprogenitors led to increased osteoblast differentiation due to increased FGF signaling

Delayed bone formation

Decreased bone formation and osteoclast-mediated resorption

AKT regulates endochondral bone formation (acting on GSK3, MTOR, and FOXO)

Osteoblast-specific knockout led to decreased bone mass

a) Decreased bone formation and b) increased bone formation 
although it has recently been suggested that Osterix gene expression can be upregulated by PI3K signaling in concert with BMP2 signaling (Mandal et al. 2010). Additional indirect evidence from targeted FOXO1 knockout mice show there is a decrease in Osterix expression implicating PI3K in the regulation of Osterix (Rached et al. 2010a,b).

\section{ATF4}

Another major transcriptional factor that is osteoblast specific is Atf4 (CREB2, cyclic AMP response element-binding protein 2) that belongs to the CREB group of transcriptional factors. Deletion of Atf4 in mice proved that it was essential for terminal osteoblast differentiation (Yang et al. 2004). ATF4 is phosphorylated by RSK2 during bone development and accumulates in osteoblasts where it enhances the synthesis of matrix proteins required for bone formation by stimulating amino acid transport into osteoblasts. ATF4 also controls the expression of 1) osteocalcin which in its uncarboxylated form modulates not only bone formation but also glucose metabolism and 2) the expression of Esp which codes for a tyrosine phosphatase (OST-PTP) in mouse osteoblasts and acts as a key negative regulator of insulin receptor activity (Yoshizawa et al. 2009). Under conditions of increased oxidative stress, FOXO1 has been shown to physically interact with ATF4 in osteoblasts to upregulate protein synthesis (Rached et al. 2010a,b). ATF4 is also important for modulating bone resorption by regulating the expression of RANKL, the protein required for osteoclast differentiation (Yoshizawa et al. 2009).

A number of other important transcriptional factors have emerged in the last half decade that regulate osteoblast differentiation such as CREB (Pearman et al. 1996), $\beta$-catenin (Day et al. 2005, Holmen et al. 2005), and Twist1 and Twist2 (Bialek et al. 2004) among others. Published data reveals that PI3K signaling and its downstream effectors like AKT interact mainly with osteoblast transcriptional factors at the level of gene transcription (Fujita et al. 2004, Rached et al. $2010 a, b)$. Insulin signaling and bone development also are intricately linked, since osteoblasts secrete and deposit osteocalcin, which can act hormonally to enhance insulin secretion and promote insulin sensitivity. Interestingly, the AKT-FOXO axis in osteoblasts also has been shown to regulate glucose homeostasis. Osteoblasts also express tyrosine kinase receptors for insulin and insulin-like growth factors (IGFs) that through ligand binding can activate downstream PI3K related events. This might be one of the major mechanisms through which PI3K signaling activates bone formation (Fig. 1). Not surprisingly, emerging evidence suggests there is also significant synergy between the AKT/ PI3K pathway and Wnt activation of $\beta$-catenin. Although the interactions between PI3K and other signaling pathways and transcription factors in osteoblasts are critical, it is clear that this system must be tightly regulated and most importantly, context specific.

\section{Pten signaling and endochondral ossification}

Through genetic engineering studies a key role in bone development has emerged for Pten, the lipid phosphatase that inactivates PI3K as well as for the PI3K/AKT pathway. Three chondrocyte and one osteoblast specific Pten conditional knockout studies have been published delineating the role of Pten during endochondral ossification. These studies are extremely valuable since they shed light on the contextspecific nature of the PI3K signaling pathway in bone and the potential interaction with other signaling pathways.

\section{Chondrocyte-specific deletion of Pten}

Ford-Hutchinson et al. (2007) used a Col2a1Cre to selectively delete Pten in mice. The Cre recombinase is under the control of the collagen $2 \mathrm{a} 1$ promoter and starts expression at $9.5 \mathrm{dpc}$ and its expression in chondrocytes is specific (Ovchinnikov et al. 2000). The authors utilized the Pten flox/flox mice described by Suzuki et al. (2001) with flox sites flanking exons 4 and 5 of Pten. Deletion of Pten led to increased chondrocyte differentiation and trabecular bone. Histological survey showed that the growth plates were abnormal with disruption in the arrangement of chondrocytes. The increase in trabecular bone was also followed by an increase in marrow adipocytes in 5-week-old animals. Another group (Yang et al. 2008) utilizing the same mice to look at chondrocyte-specific deletion of Pten, identified that loss of PTEN in the growth plate led to an increase in endoplasmic stress levels which induced HIF1 $\alpha$ activation. They concluded there was impairment in chondrocyte differentiation with Pten ablation in chondrocytes leading to dyschondroplasia thereby suggesting a mechanism through which the growth plate phenotype occurs.

A third study (Hsieh et al. 2009) that was also a chondrocyte specific model, used the Col2cre crossed to Pten flox/flox mice. These mice have only exon 5 of Pten floxed, but on utilization of the Cre showed a similar loss in PTEN protein levels in a manner identical to other Pten floxed mice (Lesche et al. 2002). The chondrocyte-specific knockout of Pten in this case also showed increased chondrocyte differentiation and growth plate defects similar to the above-mentioned studies. In addition, the long bones of these mice had an increase in marrow adipogenesis with lipoma formation. Through the use of a Rosa 26 reporter expression to study the Cre expression the authors raised the possibility that Pten also plays a role in regulating adipocyte formation.

The increased adipocytic phenotype can be explained by the activity of the Cre targeting adipocyte precursors among MSCs leading to an increase in AKT that has been shown to be necessary for adipogenesis. The phenotypes of the different chondrocyte-specific knockouts show a reasonably similar phenotype when growth plate development is compared. But, the difference among these knockouts cannot be attributed solely to deletion of Pten as there was an efficient 
knockout of Pten and activation of pAKT. On the other hand, the differences could be due to variations in the genetic background of the mice utilized for these studies. The phenotypes of the various conditional knockouts that have been reported have been summarized in Table 1 .

\section{Osteoblast-specific knockout of Pten}

Deletion of Pten in late stage osteoblasts using a Cre that is under the control of an osteocalcin promoter which starts expression at around $17 \mathrm{dpc}$ (Zhang et al. 2002) showed there is an accumulation (increase) of bone mass in bones that develop through both intramembranous and endochondral ossification. This would suggest a cell-autonomous effect of loss of PTEN on bone development. This potential mechanism was studied with calvarial osteoblasts and the authors observed a decrease in osteoblast apoptosis and an increase in MTOR signaling pathway molecules in cells from PTEN-null mice (Liu et al. 2007).

Another study using a conditional knockout approach was performed by Dermo1Cre to delete Pten in osteoprogenitors (Guntur et al. 2011). Dermo1 or twist2 Cre starts expression at around $9 \cdot 5 \mathrm{dpc}$ and targets mesenchymal cells so it works on precursors that are destined to become skeletal cells (Li et al. 1995, Yu et al. 2003). Loss of Pten in osteoprogenitors resulted in an increase in osteoblast progenitor proliferation specifically in the perichondrium and was accompanied by 1) enhanced FGF signaling; 2) increased Fgf18 expression; and 3) a decrease in Sprouty2, an inhibitor of FGF signaling, which when activated increases perichondrial osteoprogenitor proliferation and differentiation. Not surprisingly, the expression of Sprouty2, at the transcriptional level, is regulated by the FoxO group of transcriptional factors. For example, we found that overexpression of FOXO3 in C3H10T1/2 cells leads to suppression of Fgf18 expression. FGF signaling in turn activates GLI2 activity via downstream effectors, leading to osteoblast differentiation (summarized in Table 1).

Marrow adipogenesis is an alternative pathway for mesenchymal stromal cell differentiation and is dependent on the activation of several critical transcription factors, including Ppar $\gamma$. As noted, chondrocyte-specific deletion of Pten resulted in the appearance of marrow adipocytes (Hsieh et al. 2009). These findings have significant clinical implications. First, in age-related osteoporosis, osteoblast progenitor numbers are reduced while marrow adipogenesis is enhanced suggesting that lineage allocation is a critical determinant of subsequent bone turnover even in the elderly (Nuttall et al. 1998). Second, increased Ppary activation with agents such as the TZDs, force mesenchymal progenitors into the adipocyte pathway and this results in significant bone loss and a greater risk of fracture in type II diabetes mellitus. From a therapeutic perspective, agents that selectively target lineage allocation in progenitor cells might offer promise as anabolic agents, or to prevent age-related marrow adipogenesis or to set the stage for more robust skeletal formation under the appropriate circumstances.
The latter is provocative and may be critical in a number of scenarios. As shown, the Pten and the PI3K signaling pathway clearly play an important role in regulating tissuespecific progenitor cell fate (Yilmaz et al. 2006, Hill \& Wu 2009). This is further supported by findings that an increase in the activity of the FOXO is associated with a loss in bone mass and an increase in marrow adipogenesis (Moerman et al. 2004, Almeida et al. 2007). Additional evidence from Akt1/Akt2 knockout mice shows that in the absence of AKT there is an inhibition of adipocyte differentiation and that AKT is important for adipogenesis by inducing Ppar $\gamma$ expression. On the other hand, it could be argued that the increase in proliferation in Pten deleted cells maintains precursor cells as an immature population allowing for expansion of marrow adipocytes under the appropriate conditions. Experimental studies in our laboratory suggest that marrow adipogenesis is an early feature of injury models such as irradiation post bone marrow transplant or during the first $48 \mathrm{~h}$ post fracture. Maintenance of precursor cells in their 'stem-like' state by marrow adipocytes could be a critically important function by acting as 'placeholders' to allow progenitor cells time to be primed before differentiation. Ultimately, though, in the bone marrow irradiation/transplant model, adipocytes disappear either by apoptosis or by conversion to a new cell type; this is subsequently followed by rapid hematopoietic repopulation. Thus, fully understanding lineage allocation and the role of PI3K in this process is an important clinical and translational goal.

\section{PI3K, Pten signaling and intramembranous ossification}

All the above studies examined the role of PI3K signaling during endochondral ossification. However, changes in PI3K signaling during intramembranous ossification have not been studied in a systematic manner. For example, examination of the Akt1/Akt2 knockout animals shows a clear defect in intramembranous ossification that could be attributed to PI3K signaling regulating RUNX2. One study utilized the Pten flox/flox/col2a1 Cre as a model to study the effect of variation of phenotypes on the shape of the skull. As the base of the skull develops through endochondral ossification the authors observed a shortening of the skull base (Hallgrímsson et al. 2007). Furthermore, the osteocalcin Cre Pten conditional knockout exhibit increased calvarial bone density suggesting that the Pten knockout has a cell-autonomous effect on cranial bone development. In another study where AKT signaling was modulated in the skeleton by expressing a dnAKT (dominant negative) form under the control of a col2a1 promoter, skull base formation (i.e. shortening of the skull base) was affected, a finding which is nearly identical to the effect of Pten deletion on the skull base (Rokutanda et al. 2009). Studying the effect of PI3K signaling or its downstream effectors during intramembranous ossification using mouse models that have lesions in the PI3K signaling 
effectors might provide novel information about skull development and provide new therapeutic avenues to treat pathological conditions, particularly in respect to craniofacial disorders.

\section{Diverse effects of the PI3K pathway}

One of the most exciting developments in skeletal biology has been the establishment of the skeleton as a modulator of glucose and metabolic homeostasis (Lee et al. 2007, Ferron et al. 2010, Clemens \& Karsenty 2011). For example, a recent study in which FOXO1 was deleted only in osteoblasts revealed that not only was bone mass affected but so was glucose metabolism (Rached et al. 2010a,b). Though Pten specific knockouts should inactivate FOXO1 in chondrocytes and osteoblasts, and thereby lead to the metabolic effects observed with the osteoblast-specific deletion of FOXO1, none of the studies to date have addressed this question. Furthermore, osteoprogenitor-specific deletion of Pten led to FGF signaling-mediated activation of MAPK signaling showing that this arm of the signaling mechanism downstream of tyrosine kinase receptors like FGFR is also activated. Thus, studying the energy sensor kinase MTOR, the other major target of AKT (Fingar \& Blenis 2004), and its role in osteoblast differentiation would be provocative. For example, the Pten conditional knockout using an osteocalcin Cre by Liu et al. clearly showed that deletion in calvarial osteoblasts was associated with an increase in MTOR activity. In addition, the study by Ford-Hutchinson et al. (2007) revealed an increase in pP70S6K (a downstream direct target of MTOR) in the growth plate when the chondrocytes were PTEN-null. The only studies that have directly addressed these issues however, have utilized preosteoblastic cells (MC3T3E1), rats and mouse ex vivo organ cultures to inhibit MTOR using rapamycin (Alvarez-Garcia et al. 2007, Phornphutkul et al. 2008, Singha et al. 2008, Rokutanda et al. 2009, Sanchez \& He 2009). Therefore, it would be essential to study the role of MTOR signaling both in the context of loss of Pten or downstream of activation PI3K signaling during osteogenesis. In that respect, a recent study showed that loss of IGF-binding protein 2 (IGFBP2) in male mice led to an increase in PTEN protein expression in bone marrow stromal cells and calvarial osteoblasts (Demambro et al. 2008, Kawai et al. 2011). This was accompanied by an increase in marrow adiposity suggesting that enhanced Pten activity played a role in regulating bone development by controlling MSC fate. Not surprisingly, Igfbp $2-/-$ mice develop mild insulin resistance and glucose intolerance with age. In that same model, treatment of the Igfbp2-/- mice with a short polypeptide for the heparin-binding domain of the IGFBP2 molecule rescued the low bone mass phenotype and markedly suppressed PTEN expression (Kawai et al. 2011). Though there have been no lesions in humans that have been identified that affect PI3K signaling directly, syndromes like GH deficiency that cause Laron's syndrome and skeletal deficiencies, affect IGF1 levels in the body and thereby potentially modulate PI3K signaling. Moreover, PTH 1-34 and 1-84 are two peptides approved for the treatment of postmenopausal osteoporosis by enhancing bone formation (Neer et al. 2001, Greenspan et al. 2007). Although the primary mechanisms that underlie the skeletal anabolic activity of PTH are not totally defined, activation of the AKT/PI3K pathway via induction of IGF1 in osteoblasts is one pathway proven to be operative when $\mathrm{PTH}$ is administered.

\section{Conclusions}

In sum, we have shown that PTEN and PI3K are part of a critical nodal pathway in skeletal development and bone turnover. Neither the growth factor/PI3K nor Wnt/ $\beta$-catenin pathways exist in a vacuum; rather these two networks are integrated with other signaling networks. The context-specific nature of these pathways and their overlap lead to a significant level of complexity that will require further studies. Notwithstanding, experimental attempts to modify PI3K signaling to favorably impact progenitor recruitment and skeletal acquisition, or reduce the severity of craniofacial disorders, represent a major therapeutic challenge that could be extremely rewarding.

\section{Declaration of interest}

The authors declare that there is no conflict of interest that could be perceived as prejudicing the impartiality of this review.

\section{Funding}

Supported by NIH grants: AR45433 and AR 54604.

\section{References}

Alessi DR, James SR, Downes CP, Holmes AB, Gaffney PRJ, Reese CB \& Cohen P 1997 Characterization of a 3-phosphoinositide-dependent protein kinase which phosphorylates and activates protein kinase B[alpha]. Current Biology 7 261-269. (doi:10.1016/S0960-9822(06)00122-9)

Almeida M, Han L, Martin-Millan M, O’Brien CA \& Manolagas SC 2007 Oxidative stress antagonizes Wnt signaling in osteoblast precursors by diverting $\beta$-catenin from $\mathrm{T}$ cell factor- to Forkhead box O-mediated transcription. Journal of Biological Chemistry 282 27298-27305. (doi:10. 1074/jbc.M702811200)

Alvarez-Garcia O, Carbajo-Pérez E, Garcia E, Gil H, Molinos I, Rodriguez J, Ordoñez F \& Santos F 2007 Rapamycin retards growth and causes marked alterations in the growth plate of young rats. Pediatric Nephrology 22 954-961. (doi:10.1007/s00467-007-0456-8)

Ambrogini E, Maria A, Marta M-M, Ji-Hye P, Ronald AD \& Li H 2010 FoxO-mediated defense against oxidative stress in osteoblasts is indispensable for skeletal homeostasis in mice. Cell Metabolism 11 136-146. (doi:10.1016/j.cmet.2009.12.009)

Baron R \& Rawadi G 2007 Targeting the Wnt/\{beta\}-catenin pathway to regulate bone formation in the adult skeleton. Endocrinology 148 2635-2643. (doi:10.1210/en.2007-0270) 
Bialek P, Kern B, Yang X, Schrock M, Sosic D, Hong N, Wu H, Yu K, Ornitz DM, Olson EN et al. 2004 A twist code determines the onset of osteoblast differentiation. Developmental Cell 6 423-435. (doi:10.1016/S15345807(04)00058-9)

Brunet A, Bonni A, Zigmond MJ, Lin MZ, Juo P, Hu LS, Anderson MJ, Arden KC, Blenis J \& Greenberg ME 1999 Akt promotes cell survival by phosphorylating and inhibiting a Forkhead transcription factor. Cell 96 857-868. (doi:10.1016/S0092-8674(00)80595-4)

Cantley LC 2002 The phosphoinositide 3-kinase pathway. Science 296 1655-1657. (doi:10.1126/science.296.5573.1655)

Clemens TL \& Karsenty G 2011 The osteoblast: an insulin target cell controlling glucose homeostasis. Journal of Bone and Mineral Research $\mathbf{2 6}$ 677-680. (doi:10.1002/jbmr.321)

Day TF, Guo X, Garrett-Beal L \& Yang Y 2005 Wnt/2-catenin signaling in mesenchymal progenitors controls osteoblast and chondrocyte differentiation during vertebrate skeletogenesis. Developmental Cell 8 739-750. (doi:10.1016/j.devcel.2005.03.016)

DeMambro VE, Clemmons DR, Horton LG, Bouxsein ML, Wood TL, Beamer WG, Canalis E \& Rosen CJ 2008 Gender-specific changes in bone turnover and skeletal architecture in Igfbp-2-null mice. Endocrinology 149 2051-2061. (doi:10.1210/en.2007-1068)

Ducy P, Zhang R, Geoffroy V, Ridall AL \& Karsenty G 1997 Osf2/Cbfa1: a transcriptional activator of osteoblast differentiation. Cell 89 747-754. (doi:10.1016/S0092-8674(00)80257-3)

Ferron M, Wei J, Yoshizawa T, Del Fattore A, DePinho RA, Teti A, Ducy P \& Karsenty G 2010 Insulin signaling in osteoblasts integrates bone remodeling and energy metabolism. Cell 142 296-308. (doi:10.1016/j.cell.2010.06. 003)

Fingar DC \& Blenis J 2004 Target of rapamycin (TOR): an integrator of nutrient and growth factor signals and coordinator of cell growth and cell cycle progression. Oncogene 23 3151-3171. (doi:10.1038/sj.onc.1207542)

Ford-Hutchinson AF, Ali Z, Lines SE, Hallgrímsson B, Boyd SK \& Jirik FR 2007 Inactivation of Pten in osteo-chondroprogenitor cells leads to epiphyseal growth plate abnormalities and skeletal overgrowth. Journal of Bone and Mineral Research 22 1245-1259. (doi:10.1359/jbmr.070420)

Franke TF, Kaplan DR \& Cantley LC 1997 PI3K: downstream AKTion blocks apoptosis. Cell 88 435-437. (doi:10.1016/S0092-8674(00)81883-8)

Fujita T, Azuma Y, Fukuyama R, Hattori Y, Yoshida C, Koida M, Ogita K \& Komori T 2004 Runx2 induces osteoblast and chondrocyte differentiation and enhances their migration by coupling with PI3K-Akt signaling. Journal of Cell Biology 166 85-95. (doi:10.1083/jcb.200401138)

Ghosh-Choudhury N, Abboud SL, Nishimura R, Celeste A, Mahimainathan L \& Choudhury GG 2002 Requirement of BMP-2-induced phosphatidylinositol 3-kinase and Akt serine/threonine kinase in osteoblast differentiation and Smad-dependent BMP-2 gene transcription. Journal of Biological Chemistry 277 33361-33368. (doi:10.1074/jbc.M205053200)

Greenspan SL, Bone HG, Ettinger MP, Hanley DA, Lindsay R, Zanchetta JR, Blosch CM, Mathisen AL, Morris SA \& Marriott TB 2007 Effect of recombinant human parathyroid hormone (1-84) on vertebral fracture and bone mineral density in postmenopausal women with osteoporosis. Annals of Internal Medicine $\mathbf{1 4 6}$ W326-W380.

Guntur AR, Reinhold MI, Cuellar J \& Naski MC 2011 Conditional ablation of Pten in osteoprogenitors stimulates FGF signaling. Development 138 1433-1444. (doi:10.1242/dev.058016)

Hallgrímsson B, Lieberman DE, Liu W, Ford-Hutchinson AF \& Jirik FR 2007 Epigenetic interactions and the structure of phenotypic variation in the cranium. Evolution and Development 9 76-91. (doi:10.1111/j.1525142X.2006.00139.x)

Hill R \& Wu H 2009 PTEN, stem cells, and cancer stem cells. Journal of Biological Chemistry 284 11755-11759. (doi:10.1074/jbc.R800071200)

Holmen SL, Zylstra CR, Mukherjee A, Sigler RE, Faugere M-C, Bouxsein ML, Deng L, Clemens TL \& Williams BO 2005 Essential role of $\beta$-catenin in postnatal bone acquisition. Journal of Biological Chemistry 280 21162-21168. (doi:10.1074/jbc.M501900200)

Hsieh S-C, Chen N-T \& Lo SH 2009 Conditional loss of PTEN leads to skeletal abnormalities and lipoma formation. Molecular Carcinogenesis $\mathbf{4 8}$ 545-552. (doi:10.1002/mc.20491)
Kawai M, Breggia AC, DeMambro VE, Shen X, Canalis E, Bouxsein ML, Beamer WG, Clemmons DR \& Rosen CJ 2011 The heparin-binding domain of IGFBP-2 has IGF binding-independent biologic activity in the growing skeleton. Journal of Biological Chemistry 286 14670-14680. (doi:10.1074/jbc.M110.193334)

Kawamura N, Kugimiya F, Oshima Y, Ohba S, Ikeda T, Saito T, Shinoda Y, Kawasaki Y, Ogata N, Hoshi K et al. 2007 Akt1 in osteoblasts and osteoclasts controls bone remodeling. PLoS ONE 2 e1058. (doi:10.1371/journal. pone.0001058)

Koga T, Matsui Y, Asagiri M, Kodama T, de Crombrugghe B, Nakashima K \& Takayanagi H 2005 NFAT and Osterix cooperatively regulate bone formation. Nature Medicine 11 880-885. (doi:10.1038/nm1270)

Kousteni S 2011 FoxO1: a molecule for all seasons. Journal of Bone and Mineral Research 26 912-917. (doi:10.1002/jbmr.306)

Kronenberg HM 2003 Developmental regulation of the growth plate. Nature 423 332-336. (doi:10.1038/nature01657)

Lee NK, Sowa H, Hinoi E, Ferron M, Ahn JD, Confavreux C, Dacquin R, Mee PJ, McKee MD, Jung DY et al. 2007 Endocrine regulation of energy metabolism by the skeleton. Cell 130 456-469. (doi:10.1016/j.cell.2007. 05.047)

Lesche R, Groszer M, Gao J, Wang Y, Messing A, Sun H, Liu X \& Wu H 2002 $\mathrm{Cre} /$ loxP-mediated inactivation of the murine Pten tumor suppressor gene. Genesis 32 148-149. (doi:10.1002/gene.10036)

Li L, Cserjesi P \& Olson EN 1995 Dermo-1: a novel twist-related bHLH protein expressed in the developing dermis. Developmental Biology 172 280-292. (doi:10.1006/dbio.1995.0023)

Li J, Yen C, Liaw D, Podsypanina K, Bose S, Wang SI, Puc J, Miliaresis C, Rodgers L, McCombie R et al. 1997 PTEN, a putative protein tyrosine phosphatase gene mutated in human brain, breast, and prostate cancer. Science 275 1943-1947. (doi:10.1126/science.275.5308.1943)

Liu X, Bruxvoort KJ, Zylstra CR, Liu J, Cichowski R, Faugere M-C, Bouxsein ML, Wan C, Williams BO \& Clemens TL 2007 Lifelong accumulation of bone in mice lacking Pten in osteoblasts. PNAS 104 2259-2264. (doi:10.1073/pnas.0604153104)

Maehama T \& Dixon JE 1998 The tumor suppressor, PTEN/MMAC1, dephosphorylates the lipid second messenger, phosphatidylinositol 3,4,5trisphosphate. Journal of Biological Chemistry 273 13375-13378. (doi:10. 1074/jbc.273.22.13375)

Mandal C, Drissi H, Ghosh Choudhury G \& Ghosh-Choudhury N 2010 Integration of phosphatidylinositol 3-kinase, Akt kinase, and Smad signaling pathway in BMP-2-induced Osterix expression. Calcified Tissue International 87 533-540. (doi:10.1007/s00223-010-9419-3)

Manning BD \& Cantley LC 2007 AKT/PKB signaling: navigating downstream. Cell 129 1261-1274. (doi:10.1016/j.cell.2007.06.009)

Moerman EJ, Teng K, Lipschitz DA \& Lecka-Czemik B 2004 Aging activates adipogenic and suppresses osteogenic programs in mesenchymal marrow stroma/stem cells: the role of PPAR $-\gamma 2$ transcription factor and TGF- $\beta$ / BMP signaling pathways. Aging Cell 3 379-389. (doi:10.1111/j.1474-9728. 2004.00127.x)

Mukherjee A, Wilson EM \& Rotwein P 2010 Selective signaling by Akt2 promotes bone morphogenetic protein 2-mediated osteoblast differentiation. Molecular and Cellular Biology 30 1018-1027. (doi:10.1128/MCB. 01401-09)

Mundlos S, Otto F, Mundlos C, Mulliken JB, Aylsworth AS, Albright S, Lindhout D, Cole WG, Henn W, Knoll JHM et al. 1997 Mutations involving the transcription factor CBFA1 cause cleidocranial dysplasia. Cell 89 773-779. (doi:10.1016/S0092-8674(00)80260-3)

Myers MP, Pass I, Batty IH, Van der Kaay J, Stolarov JP, Hemmings BA, Wigler MH, Downes CP \& Tonks NK 1998 The lipid phosphatase activity of PTEN is critical for its tumor supressor function. PNAS 95 13513-13518. (doi:10.1073/pnas.95.23.13513)

Nakashima K, Zhou X, Kunkel G, Zhang Z, Deng JM, Behringer RR \& de Crombrugghe B 2002 The novel zinc finger-containing transcription factor Osterix is required for osteoblast differentiation and bone formation. Cell 108 17-29. (doi:10.1016/S0092-8674(01)00622-5)

Neer RM, Arnaud CD, Zanchetta JR, Prince R, Gaich GA, Reginster J-Y, Hodsman AB, Eriksen EF, Ish-Shalom S, Genant HK et al. 2001 Effect of 
parathyroid hormone (1-34) on fractures and bone mineral density in postmenopausal women with osteoporosis. New England Journal of Medicine 344 1434-1441. (doi:10.1056/NEJM200105103441904)

Nishio Y, Dong Y, Paris M, O'Keefe RJ, Schwarz EM \& Drissi H 2006 Runx2-mediated regulation of the zinc finger Osterix/Sp7 gene. Gene 372 62-70. (doi:10.1016/j.gene.2005.12.022)

Nuttall ME, Patton AJ, Olivera DL, Nadeau DP \& Gowen M 1998 Human trabecular bone cells are able to express both osteoblastic and adipocytic phenotype: implications for osteopenic disorders. Journal of Bone and Mineral Research 13 371-382. (doi:10.1359/jbmr.1998.13.3.371)

Otto F, Thornell AP, Crompton T, Denzel A, Gilmour KC, Rosewell IR, Stamp GWH, Beddington RSP, Mundlos S, Olsen BR et al. 1997 Cbfa1, a candidate gene for cleidocranial dysplasia syndrome, is essential for osteoblast differentiation and bone development. Cell 89 765-771. (doi:10. 1016/S0092-8674(00)80259-7)

Ovchinnikov DA, Deng JM, Ogunrinu G \& Behringer RR 2000 Col2a1directed expression of Cre recombinase in differentiating chondrocytes in transgenic mice. Genesis 26 145-146. (doi:10.1002/(SICI)1526968X(200002)26:2<145::AID-GENE14>3.0.CO;2-C)

Pearman AT, Chou W-Y, Bergman KD, Pulumati MR \& Partridge NC 1996 Parathyroid hormone induces c-fos promoter activity in osteoblastic cells through phosphorylated cAMP response element (CRE)-binding protein binding to the major CRE. Journal of Biological Chemistry 271 25715-25721. (doi:10.1074/jbc.271.41.25715)

Peng X-d, Xu P-Z, Chen M-L, Hahn-Windgassen A, Skeen J, Jacobs J, Sundararajan D, Chen WS, Crawford SE, Coleman KG et al. 2003 Dwarfism, impaired skin development, skeletal muscle atrophy, delayed bone development, and impeded adipogenesis in mice lacking Akt1 and Akt2. Genes and Development 17 1352-1365. (doi:10.1101/gad.1089403)

Phornphutkul C, Wu K-Y, Auyeung V, Chen Q \& Gruppuso PA 2008 mTOR signaling contributes to chondrocyte differentiation. Developmental Dynamics 237 702-712. (doi:10.1002/dvdy.21464)

Rached M-T, Kode A, Silva BC, Jung DY, Gray S, Ong H, Paik J-H, DePinho RA, Kim JK, Karsenty G et al. 2010a FoxO1 expression in osteoblasts regulates glucose homeostasis through regulation of osteocalcin in mice. Journal of Clinical Investigation 120 357-368. (doi:10.1172/JCI39901)

Rached M-T, Kode A, Xu L, Yoshikawa Y, Paik J-H, DePinho RA \& Kousteni S 2010b FoxO1 is a positive regulator of bone formation by favoring protein synthesis and resistance to oxidative stress in osteoblasts. Cell Metabolism 11 147-160. (doi:10.1016/j.cmet.2010.01.001)

Rokutanda S, Fujita T, Kanatani N, Yoshida CA, Komori H, Liu W, Mizuno A \& Komori T 2009 Akt regulates skeletal development through GSK3, mTOR, and FoxOs. Developmental Biology 328 78-93. (doi:10. 1016/j.ydbio.2009.01.009)

Sanchez C \& He Y-Z 2009 Bone growth during rapamycin therapy in young rats. BMC Pediatrics 9 3. (doi:10.1186/1471-2431-9-3)

Sarbassov DD, Guertin DA, Ali SM \& Sabatini DM 2005 Phosphorylation and regulation of Akt/PKB by the rictor-mTOR complex. Science 307 1098-1101. (doi:10.1126/science.1106148)

Secreto FJ, Hoeppner LH \& Westendorf JJ 2009 Wnt signaling during fracture repair. Current Osteoporosis Reports 7 64-69. (doi:10.1007/s11914-009_ 0012-5)

Singha UK, Jiang Y, Yu S, Luo M, Lu Y, Zhang J \& Xiao G 2008 Rapamycin inhibits osteoblast proliferation and differentiation in MC3T3-E1 cells and primary mouse bone marrow stromal cells. Journal of Cellular Biochemistry 103 434-446. (doi:10.1002/jcb.21411)
Suzuki A, Yamaguchi MT, Ohteki T, Sasaki T, Kaisho T, Kimura Y, Yoshida R, Wakeham A, Higuchi T, Fukumoto M et al. 2001 T cell-specific loss of Pten leads to defects in central and peripheral tolerance. Immunity 14 523-534. (doi:10.1016/S1074-7613(01)00134-0)

Ulici V, Hoenselaar KD, Agoston H, McErlain DD, Umoh J, Chakrabarti S, Holdsworth DW \& Beier F 2009 The role of Akt1 in terminal stages of endochondral bone formation: angiogenesis and ossification. Bone $\mathbf{4 5}$ 1133-1145. (doi:10.1016/j.bone.2009.08.003)

Williams BO \& Insogna KL 2009 Where Wnts went: the exploding field of Lrp5 and Lrp6 signaling in bone. Journal of Bone and Mineral Research 24 171-178. (doi:10.1359/jbmr.081235)

Yang X, Matsuda K, Bialek P, Jacquot S, Masuoka HC, Schinke T, Li L, Brancorsini S, Sassone-Corsi P, Townes TM et al. 2004 ATF4 is a substrate of RSK2 and an essential regulator of osteoblast biology: implication for Coffin-Lowry syndrome. Cell 117 387-398. (doi:10.1016/S00928674(04)00344-7)

Yang G, Sun Q, Teng Y, Li F, Weng T \& Yang X 2008 PTEN deficiency causes dyschondroplasia in mice by enhanced hypoxia-inducible factor $1 \alpha$ signaling and endoplasmic reticulum stress. Development 135 3587-3597. (doi:10.1242/dev.028118)

Yang S, Xu H, Yu S, Cao H, Fan J, Ge C, Fransceschi RT, Dong HH \& Xiao G 2011 FOXO1 mediates IGF1/insulin regulation of osteocalcin expression by antagonizing RUNX2 in osteoblasts. Journal of Biological Chemistry 286 19149-19158. (doi:10.1074/jbc.M110.197905)

Yilmaz ÖH, Valdez R, Theisen BK, Guo W, Ferguson DO, Wu H \& Morrison SJ 2006 Pten dependence distinguishes haematopoietic stem cells from leukaemia-initiating cells. Nature 441 475-482. (doi:10.1038/ nature04703)

Yoshizawa T, Hinoi E, Jung DY, Kajimura D, Ferron M, Seo J, Graff JM, Kim JK \& Karsenty G 2009 The transcription factor ATF4 regulates glucose metabolism in mice through its expression in osteoblasts. Journal of Clinical Investigation 119 2807-2817. (doi:10.1172/ JCI39366)

Yu K, Xu J, Liu Z, Sosic D, Shao J, Olson EN, Towler DA \& Ornitz DM 2003 Conditional inactivation of FGF receptor 2 reveals an essential role for FGF signaling in the regulation of osteoblast function and bone growth. Development 130 3063-3074. (doi:10.1242/dev.00491)

Zhang M, Xuan S, Bouxsein ML, von Stechow D, Akeno N, Faugere MC, Malluche H, Zhao G, Rosen CJ, Efstratiadis A et al. 2002 Osteoblastspecific knockout of the insulin-like growth factor (IGF) receptor gene reveals an essential role of IGF signaling in bone matrix mineralization. Journal of Biological Chemistry 277 44005-44012. (doi:10.1074/jbc. M208265200)

Zhou X, Zhang Z, Feng JQ, Dusevich VM, Sinha K, Zhang H, Darnay BG \& de Crombrugghe B 2010 Multiple functions of Osterix are required for bone growth and homeostasis in postnatal mice. PNAS 107 12919-12924. (doi:10.1073/pnas.0912855107)

\section{Received in final form 6 June 2011 \\ Accepted 14 June 2011 \\ Made available online as an Accepted Preprint 14 June 2011}

